\title{
Crosslinked PolyCyclodextrin/PolyBenzoxazine electrospun microfibers for selective removal of methylene blue from an aqueous system
}

\author{
Yelda Ertas Dogan ${ }^{\mathrm{a}}$, Bekir Satilmis ${ }^{\mathrm{a}, \mathrm{b}}$, Tamer Uyar ${ }^{\mathrm{a}, \mathrm{c}, *}$ \\ ${ }^{a}$ Institute of Materials Science \& Nanotechnology, Bilkent University, Ankara 06800, Turkey \\ ${ }^{\mathrm{b}}$ Department of Medical Services and Techniques, Vocational School of Health Services, Kirsehir Ahi Evran University, Kirsehir 40100, Turkey \\ ${ }^{\mathrm{c}}$ Department of Fiber Science \& Apparel Design, College of Human Ecology, Cornell University, Ithaca, NY 14853, USA
}

\section{A R T I C L E I N F O}

\section{Keywords:}

Cyclodextrin

Polybenzoxazine

Electrospinning

Microfibers

Water treatment

Selective dye removal

\begin{abstract}
A B S T R A C T
In this study, a blend solution of hydroxypropyl- $\beta$-cyclodextrin (HP $\beta C D)$ and benzoxazine monomer (BA-a) was prepared in dimethylformamide to obtain HP $\beta C D / B A-a$ microfibers by electrospinning technique. The electrospun HP $\beta C D / B A-a$ microfibers were then thermally cured to obtain crosslinked PolyHP $\beta C D / P o l y B A-a$ microfibers. The compositions of $\operatorname{HP} \beta C D(120 \%, w / v)$ and BA-a $(25 \%, w / v)$ were determined as an optimum concentration for producing bead-free and uniform microfibers from blend of HP $\beta C D$ and BA-a (HP $\beta C D / B A-a)$. Afterwards, the HP $\beta C D / B A-a$ microfibers were thermally cured using step-wise curing method to obtain waterinsoluble crosslinked PolyHP $\beta C D /$ PolyBA-a fibrous membrane (FM). However, the fibrous structure of PolyHP $\beta C D / P o l y B A-a$ membrane was subjected to some morphological deformation during thermal curing. Therefore, citric acid (CTR, $5 \%$ and $15 \%, w / v$ ) was incorporated into blend of HP $\beta C D 15 / \mathrm{BA}-\mathrm{a}$ and it was named as HP $\beta C D x / B A-a$ where $\mathrm{x}$ represents the amount of CTR $(w / v)$ in the system. Blend solution of HP $\beta C D 15 / \mathrm{BA}-\mathrm{a}$ was electrospun into microfibers to facilitate the crosslinking and to improve thermal resistance of the crosslinked fibrous membrane (PolyHPßCD15/PolyBA-a). Structural changes and thermal properties of the microfibers before and after curing were studied. Scanning electron microscopy was further used to monitor the morphology and stability of crosslinked PolyHP $\beta C D /$ PolyBA-a microfibers in water and organic solvents. Consequently, PolyHP $\beta C D 15 /$ PolyBA-a microfibers showed an enhanced structural stability in water and organic solvents along with thermal resistance, indicating successful crosslinking. Afterwards, the molecular separation ability of self-standing PolyHPßCD15/PolyBA-a FM was evaluated using dye mixture of Methylene Blue (MB) and Methyl Orange (MO). While both dye molecules are able to form a host-guest interaction between cyclodextrin molecules, crosslinked PolyHPßCD15/PolyBA-a FM showed sorption selectivity against cationic MB dye due to favorable electrostatic attractions between MB and HP $\beta C D$ compared to anionic MO dye and HP $\beta C D$. In addition to selective sorption behavior of MB dye over MO dye, crosslinked PolyHP $\beta C D 15 /$ PolyBA-a FM exhibited a decent adsorption capacity for $\mathrm{MB}$ in water.
\end{abstract}

\section{Introduction}

Cyclodextrins (CDs) are cyclic oligosaccharides having cage-like molecular structure containing glucopyranose units joined together by $\alpha(1 \rightarrow 4)$ linkage. CDs are produced by enzymatic degradation of starch, hence, they are natural, non-toxic and edible $[1,2]$. The native CDs are classified as $\alpha-C D(6), \beta-C D(7)$ and $\gamma$-CD (8) based on the number of glucopyranose units in their molecular structures [1]. CDs are truncated cone-shaped molecules that have hydrophobic cavity and hydrophilic outer surface, which enables the formation of host-guest interactions $[1,3]$. Therefore, they have been successfully used for various applications such as pharmaceutical [4-8], bio-medical [8-12], food [13,14] and food packaging [14,15], textiles [16] and environmental applications such as filtrations [17-20]. Natives CDs can be modified to obtained highly water-soluble CDs such as hydroxypropyl$\beta$-cyclodextrin (HP $\beta C D$ ), hydroxypropyl- $\gamma$-cyclodextrin (HP $\gamma \mathrm{CD}$ ) and methyl- $\beta$-cyclodextrin (M $\beta C D$ ) compared to their native CDs [21]. High water solubility may further extend the potential use of CDs, particularly in electrospinning which is a straightforward, controllable and cost-effective method for producing functional microfibers/nanofibers from variety of modified CDs [22]. The high solubility of CDs empowers the electrospinning of various CD functional fibers and their fibrous membranes (FMs) from their water solution. Hence, certain efforts have been reported recently for the development of $\mathrm{CD}$ based fibrous

\footnotetext{
* Corresponding author at: Department of Fiber Science \& Apparel Design, College of Human Ecology, Cornell University, Ithaca, NY 14853, USA.

E-mail address: tu46@cornell.edu (T. Uyar).
} 
structures by electrospinning using modified CDs [22-26]. CD functional electrospun fibers have potentials in numerous applications such as drug delivery [7,27], food [28] and molecular filtration [29], yet, the use of $\mathrm{CD}$ functional electrospun fibers for water filtration has limitations due to the high solubility of $\mathrm{CD}$ fibers in water and in some organic solvents. To overcome this challenge, in our recent studies [30-32], our group has shown that chemical crosslinking of CDs has improved the structural integrity of these $\mathrm{CD}$ based fibrous membranes in water and organic solvents. Thus, the CD based FMs can be effectively used in water treatment applications such as removal of organics from waste water [30-32]. Since contaminated water poses a threat to environment, effective separation of organic contaminants from waste water is indispensable, yet, it is still a quite challenging task, thus, CD functional FMs can be quite effective for waste water treatment [17,30-37].

Benzoxazines are relatively new class of thermosetting phenolic resins that can be polymerized/crosslinked by thermal curing, resulting in polybenzoxazines which demonstrate outstanding thermal, mechanical and physicochemical properties, including high chemical resistance, high glass transition temperature and high char yield $[38,39]$. In addition to these, benzoxazines exhibit no by-products during their thermal crosslinking [40]. Therefore, polybenzoxazine based materials are demanding for constructing high performance materials [39]. Polybenzoxazines have been mostly employed in the form of bulk $[38,39]$, yet, recent studies were reported related to membranes $[41,42]$ and nanofibers [43-45] based on polybenzoxazines.

Structural and thermal properties of CD functionalized electrospun fibers could be improved by incorporating benzoxazine (BA-a) resins. Therefore, in this study, we have performed electrospinning of CD/BA-a blend fibers, which was then thermally cured to obtain crosslinked Polycyclodextrin/Polybenzoxazine (PolyCD/PolyBA-a) microfibers. Our aim was to develop PolyCD/PolyBA-a crosslinked microfibers having unique properties of CDs and polybenzoxazines which are chemically and thermally stable, and suitable as insoluble fibrous membrane for water treatment application.

To the best of our knowledge, this will be the first report related to electrospun crosslinked PolyCD/PolyBA-a fibers and the proof of concept study for their use in waste water treatment, specifically for the removal of organic dyes from water. Herein, electrospinning of uniform microfibers from blend of hydroxypropyl- $\beta$-cyclodextrin (HP $\beta C D)$ and benzoxazine (BA-a) monomer along with citric acid (CTR) has been successfully performed. The electrospun $\mathrm{HP} \beta \mathrm{CD} / \mathrm{BA}-\mathrm{a}$ microfibers were then thermally cured to obtain water-insoluble (PolyHP $\beta C D / P o l y B A-a)$ fibrous membrane (FM). Afterwards, molecular entrapment ability of PolyHP $\beta C D / P o l y B A-a$ FM was evaluated using a mixture of Methylene Blue (MB) and Methyl Orange (MO) dyes as model compounds, revealing a selective adsorption of MB dye over MO dye by PolyHP $\beta C D /$ PolyBA-a FM. Additionally, adsorption capacity of PolyHP $\beta C D / P o l y B A-$ a FM was investigated for MB dye in water.

\section{Experimental}

\subsection{Materials}

Hydroxypropyl- $\beta$-cyclodextrin $\left(\mathrm{HP} \beta \mathrm{CD}\right.$, Cavasol$^{\circledR}$ W7 HP) was kindly supplied as a gift sample by Wacker Chemie GmbH (Germany). Bisphenol A (97\%), paraformaldehyde (95\%), aniline (99.5\%), citric acid monohydrate (CTR, 99\%), acetonitrile (ACN, $\geq 99.5 \%$ ), acetone ( $\geq 99 \%$ ), methanol ( $\mathrm{MeOH}, \geq 99.8 \%$ ), ethanol (EtOH, $\geq 99.8 \%$ ), chloroform $\left(\mathrm{CHCl}_{3}, 99-99.4 \%\right)$, dimethylformamide (DMF, $\geq 99.8 \%$ ), dimethyl sulfoxide (DMSO, $\geq 99.9 \%$ ), tetrahydrofuran (THF, $\geq 99.9 \%$ ) and Methylene Blue (molecular formula: $\mathrm{C}_{16} \mathrm{H}_{18} \mathrm{ClN}_{3} \mathrm{~S} \cdot 3 \mathrm{H}_{2} \mathrm{O}$; molecular weight: 373.9) were obtained from Sigma Aldrich and were used as received. Methyl Orange (molecular formula: $\mathrm{C}_{14} \mathrm{H}_{14} \mathrm{~N}_{3} \mathrm{NaO}_{3} \mathrm{~S}$; molecular weight: 327.3 ) was purchased from Merck and was used without further purification.

\subsection{Synthesis of benzoxazine monomer (BA-a)}

Benzoxazine monomer (BA-a) monomer was synthesized and characterized as reported in our previous study by using solventless method [45]. Briefly, bisphenol-A $(0.05 \mathrm{~mol})$, aniline $(0.1 \mathrm{~mol})$ and paraformaldehyde $(0.2 \mathrm{~mol})$ were first mixed at room temperature and heated to $110^{\circ} \mathrm{C}$ in a $100 \mathrm{ml}$ round bottom flask. Then, the mixture was maintained at this temperature in an oil bath for $2 \mathrm{~h}$, while its stirring. The crude product was dissolved in chloroform after cooling down to room temperature. The product was extracted by $3 \mathrm{M} \mathrm{NaOH}$, and was dried using sodium sulfate. Subsequently, chloroform was evaporated with a rotary evaporator. It was dried in a vacuum oven at $70^{\circ} \mathrm{C}$ for overnight. The final product was grinded by mortar and pestle to obtain a bright yellow powder.

\subsection{Preparation of $H P \beta C D$ and $H P \beta C D / B A-a$ precursor solutions}

The solution of $\operatorname{HP} \beta C D(120 \%, w / v)$, was prepared by using DMF as a solvent. The clear and homogeneous solution was obtained after stirring at room temperature for $1.5 \mathrm{~h}$. For the preparation of $\mathrm{HP} \beta \mathrm{CD} /$ BA-a mixture solutions, BA-a powder was dissolved in DMF at room temperature prior to the addition of $\mathrm{HP} \beta C D$. Then, the mixture was stirred well at room temperature for the complete dissolution. Various compositions of $\mathrm{HP} \beta \mathrm{CD} / \mathrm{BA}$-a solutions were prepared by changing the ratio of $\mathrm{HP} \beta C D$ and BA-a from 75:50, 75:75 and 120:25 (w:w/v) to determine optimum concentration. Besides, citric acid (CTR, $5 \%$ and $15 \% w / v)$ was added to $\mathrm{HP} \beta \mathrm{CD} / \mathrm{BA}-\mathrm{a}$ solutions as a crosslinker to provide complete crosslinking and to maintain fiber morphology during thermal treatment. Furthermore, the influence of CTR and BA-a in the curing process of the microfibers was investigated using different control groups as depicted in Table 1 which reveals the sample codes and sample compositions. Throughout the study, the amount of HP $\beta C D$ $(120 \% w / v)$ and BA-a $(25 \% w / v)$ was kept constant while adjusting the amount of CTR. Therefore, samples were coded as HP $\beta C D x / B A-a$ where $\mathrm{x}$ represents the amount of CTR in blend solution.

\subsection{Electrospinning of $H P \beta C D / B A-a$ microfibers}

The solutions were transferred in $1 \mathrm{ml}$ syringes which was equipped with 18-gauge blunt needle. The syringe was placed horizontally on a syringe pump (KD Scientific, KDS 101). A stationary collector was covered by aluminum foil and placed across the syringe to collect microfibers. Electrospinning was achieved by applying optimized

Table 1

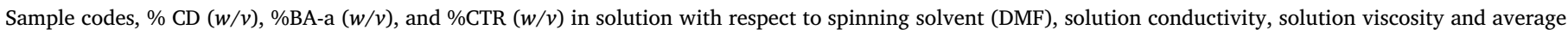
fiber diameter of microfibers.

\begin{tabular}{|c|c|c|c|c|c|c|}
\hline Sample & $\% \mathrm{CD}(w / v)$ & $\% \mathrm{BA}-\mathrm{a}(w / v)$ & $\% \operatorname{CTR}(w / v)$ & Conductivity $\left(\mu \mathrm{S} \mathrm{cm}^{-1}\right)$ & Viscosity (Pa s) & Average fiber diameter $(\mu \mathrm{m})$ \\
\hline $\mathrm{HP} \beta \mathrm{CD}$ & 120 & - & - & 2.26 & 0.162 & $1.10 \pm 0.20$ \\
\hline HP $\beta C D 15$ & 120 & - & 15 & 1.77 & 0.321 & $1.10 \pm 0.33$ \\
\hline HР $\beta C D / B A-a$ & 120 & 25 & - & 1.49 & 0.329 & $1.11 \pm 0.23$ \\
\hline HPßCD5/BA-a & 120 & 25 & 5 & 1.62 & 0.458 & $1.12 \pm 0.30$ \\
\hline HР $\beta C D 15 / B A-a$ & 120 & 25 & 15 & 1.48 & 0.803 & $1.46 \pm 0.35$ \\
\hline
\end{tabular}


parameters; $15 \mathrm{kV}$ voltage, $1 \mathrm{ml} \mathrm{h}^{-1}$ flow rate and $16 \mathrm{~cm}$ distance from the collector. Then, the collected fibrous mats were kept in a fume hood for overnight to remove any residual solvent if present.

\subsection{Curing studies of $H P \beta C D / B A-a$ microfibers}

Stepwise curing strategy was applied on a HP $\beta C D / B A-a$ microfibers which were first placed in a standard oven heated at $150{ }^{\circ} \mathrm{C}$ and kept for an hour at this temperature. Then, the temperature was increased by $25^{\circ} \mathrm{C}$ intervals until to reach $225^{\circ} \mathrm{C}$. The samples were kept at each temperature intervals for an hour to initiate ring opening of the oxazine ring and to achieve crosslinking, resulting PolyHP $\beta C D / P o l y P B A-a$ microfibers.

\subsection{Solubility test of PolyHPßCD/PolyBA-a fibrous membranes (FMs)}

Solubility of crosslinked PolyHP $\beta C D / P o l y B A-a$ FMs was investigated using common organic solvents; acetone, ACN, chloroform, DMF, DMSO, ethanol, methanol, THF and water. A piece of PolyHP $\beta C D /$ PolyBA-a FM was immersed into solvents for overnight, and then they were dried at room temperature.

\subsection{Methods}

Conductivity of the solutions was tested for thrice and mean values were determined at room temperature by a conductivity meter (FiveEasy Cond meter F30, Mettler Toledo). Anton Paar MCR 301 rheometer was utilized to obtain viscosity values of the solutions at $25^{\circ} \mathrm{C}$, and the viscosity value at $100 \mathrm{~s}^{-1}$ was reported. Scanning electron microscopy (FEI Quanta $200 \mathrm{FEG}$ ) imaging was employed to characterize the morphology of the electrospun microfibers. The Fourier-transform infrared (FT-IR) spectroscopy measurement was performed to investigate the structure of BA-a monomer and the fibrous membranes using Bruker-VERTEX70 spectrometer in the range of $400-4000 \mathrm{~cm}^{-1}$. A solution of BA-a monomer in $\mathrm{CDCl}_{3}$ was measured by Proton nuclear magnetic resonance $\left({ }^{1} \mathrm{H}\right.$ NMR) Spectroscopy (Bruker Advance III $400 \mathrm{MHz}$ ) to confirm the chemical structure. Thermal properties of the samples were monitored by thermogravimetric analyzer (TGA, TA Q500). TGA was performed in the temperature range from 25 to $800{ }^{\circ} \mathrm{C}$ under the continuous flow of nitrogen. UV-Vis Spectroscopy (Varian Cary 5000) was used to determine the dye adsorption ability of PolyHP $\beta C D 15 /$ PolyBA-a FM.

\subsection{Removal of dye molecules from water by PolyHP $\beta C D 15 / P o l y B A-a$ FM}

Dye removal ability and the selectivity of PolyHP 3 CD15/PolyBA-a FM were determined using two different dyes; Methylene Blue (MB) and Methyl Orange (MO). $5 \mathrm{mg}$ of sample was added into $5 \mathrm{ml}$ of dye solutions. The concentrations of the dye solutions were varied from $10 \mathrm{mg} \mathrm{L}^{-1}$ to $100 \mathrm{mg} \mathrm{L}^{-1}$ and agitated at $150 \mathrm{rpm}$ on a mechanical shaker under ambient conditions for $6 \mathrm{~h}$. Time dependent removal efficiency was studied by measuring the absorbance of the solutions from $5 \mathrm{~min}$ to $360 \mathrm{~min}$. Adsorption capacity was calculated based on the Eq. (1).

$q_{e}=\frac{\left(C_{0}-C_{e}\right)}{C_{0}}$

where $q_{\mathrm{e}}$ is adsorption capacity ( $\mathrm{mg} \mathrm{g}^{-1}$ ), $C_{0}$ and $C_{\mathrm{e}}$ are the concentration of MB dye in the aqueous solution before and after the adsorption, respectively $\left(\mathrm{mg} \mathrm{L}^{-1}\right), V$ is the volume of the solution (L), and $m$ is the weight of the PolyHP $\beta$ CD15/PolyBA-a FM.

Regeneration of PolyHP $\beta C D 15 /$ PolyBA-a FM was investigated using continuous adsorption/desorption experiments. First, $5 \mathrm{mg}$ of PolyHP $\beta C D 15 /$ PolyBA-a FM was added into $5 \mathrm{ml}, 10 \mathrm{mg} \mathrm{L}^{-1}$ of MB solution and agitated until the equilibrium. Then, the membrane was placed in methanol solution. Following that the solution was acidified using $1 \mathrm{M} \mathrm{HCl}$ to remove the adsorb MB. Adsorption/desorption experiment was performed for four consecutive cycles.

\section{Result and discussion}

Electrospinning of microfibers/nanofibers from polymeric [46] and non-polymeric systems [22] significantly depends on two critical factors that are solution concentration and solution viscosity. Polymeric systems require certain solution concentration to achieve sufficient entanglements, similarly, non-polymeric systems such as cyclodextrins need an appropriate solution concentration to create adequate aggregates and hydrogen-bonding interactions to obtain uniform fiber formation in electrospinning $[22,25]$. In order to perform electrospinning of uniform fibers, the optimal solution concentration could be different depending on source of the materials used (purity, etc.), type of solvent used, applied electrospinning parameters (voltage, flow rate, collection distance, etc.) and environmental conditions (temperature, humidity, etc.) and such optimal solution concentration might be different to attain required viscosity values for the same molecule [22,25]. For instance, the electrospinning of fibers from HP $\beta C D$ molecules was reported by different research groups $[22,23,25]$. While Zhang et al. [25] were able to obtain uniform fibers by $\sim 60 \%(w / v)$ HP $\beta C D$ solution concentration in DMF, our group has reported to obtain uniform fibers at $120 \%(w / v)$ HP $\beta C D$ concentration in the same solvent [22]. Therefore, we have used $120 \%(w / v)$ HP $\beta C D$ concentration in DMF to obtain bead-free and uniform HP $\beta C D$ microfibers as reported in our previous study [22]. However, the electrospun HP $\beta C D$ microfibers quickly lose their structural integrity and readily dissolve in an aqueous environment which limits the applications of such CD based functional fibers in water treatment and liquid filtration. To alleviate this problem, HP $\beta C D$ microfibers could be crosslinked with appropriate crosslinkers [30,31].

As it is well known, benzoxazine monomer (BA-a) undergoes a ring opening mechanism and polymerizes by thermal curing, forming polybenzoxazine (PolyBA-a) structure [47]. Therefore, we have incorporated BA-a to crosslink HP $\beta C D$ microfibers by simple blending and subsequent curing method with the aim of not only to improve solvent stability but also to enhance the thermal properties of microfibers while maintaining the molecular selectivity of CD cavity. Fig. 1 shows the chemical structures of HP $\beta C D$ and BA-a, schematic set up for electrospinning of $\mathrm{HP} \beta \mathrm{CD} / \mathrm{BA}-\mathrm{a}$ microfibers and digital images of $\mathrm{HP} \beta \mathrm{CD} / \mathrm{BA}-\mathrm{a}$ and cured PolyHP $\beta \mathrm{CD} /$ PolyBA-a fibrous membranes (FMs).

Our preliminary research has shown that reducing HP $\beta C D$ concentration causes beaded fibers due to the insufficient amount of $C D$ aggregates [22], whereas increasing BA-a concentration leads to an increase in fiber thickness. Following the preliminary attempts, the composition of $\operatorname{HP} \beta C D(120 \%, w / v) / B A-a(25 \%, w / v)$ was chosen for further investigation, since it enables the formation of bead-free and uniform microfibers while maintaining the high content of HP $\beta C D$ in the fiber matrix. Since the main goal of this study was to achieve selective removal of dye molecules from water, the amount of HP $\beta C D$ would play a prominent role in the electrospun fiber matrix. Fig. 2(a1) presents SEM image of HP $\beta C D / B A-a$. Then, curing study was performed on $\mathrm{HP} \beta \mathrm{CD} / \mathrm{BA}$-a fibrous sample by starting from $150^{\circ} \mathrm{C}$ and temperature increased step-wisely up to $225^{\circ} \mathrm{C}$ in order to obtain crosslinked PolyHP $\beta C D /$ PolyBA-a. However, high curing temperature $\left(225^{\circ} \mathrm{C}\right)$ caused structural deformation on the fibrous morphology of PolyHP $\beta C D / P o l y B A-a$, resulted in fused and interconnected fibers which are evidenced in Fig. 2(a2). Therefore, we slightly modified the content of the electrospinning solution in order to develop more stable and highly crosslinked PolyHP $\beta C D / P o l y B A-a$ microfibers. For the purpose of reducing the structural deformation in HP $\beta C D / B A-a$ microfibers during curing, citric acid (CTR, 5\% and 15\%, $w / v$ ) was introduced as a crosslinker into the HP $\beta \mathrm{CD} / \mathrm{BA}-\mathrm{a}$ mixture solutions. The samples were coded as HP $\beta \mathrm{CDx} / \mathrm{BA}-\mathrm{a}$, to express the existence and the amount of CTR $(\%, w / v)$ in the DMF solution. In addition to these solutions, HP $\beta C D 15$, 


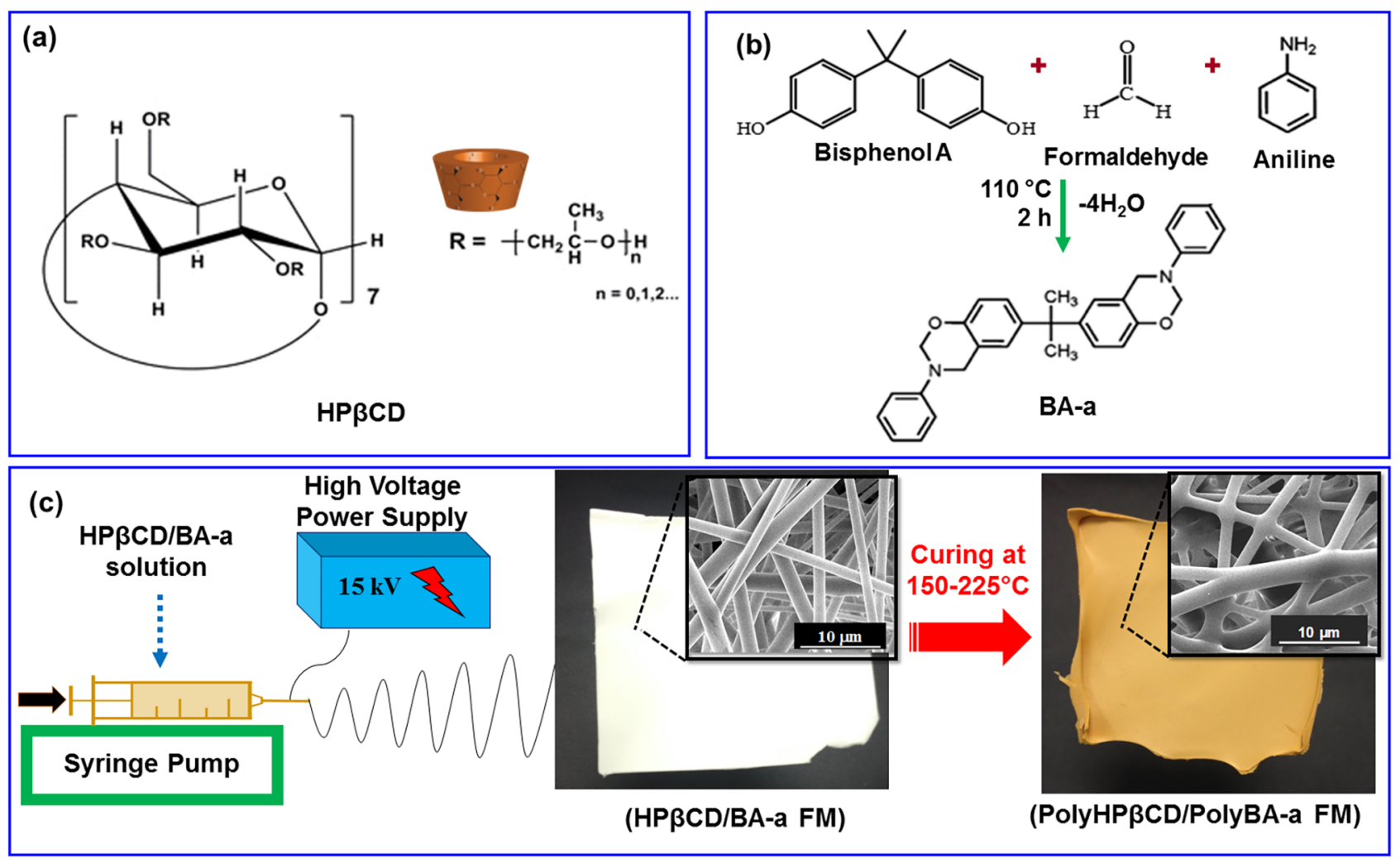

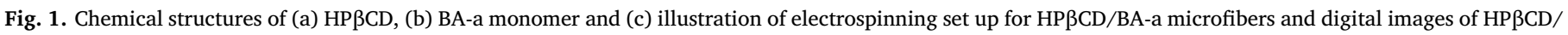
BA-a and cured PolyHP $\beta C D /$ PolyBA-a FMs.

which denotes $\operatorname{HP} \beta \operatorname{CD}(120 \%, w / v) / \operatorname{CTR}(15 \%, w / v)$ mixture was also prepared as a control sample to study the influence of CTR and BA-a on the crosslinking behavior of HP $\beta C D$ microfibers. The bead-free and uniform electrospun microfibers (HP $\beta C D / B A-a, H P \beta C D 15$, HP $\beta C D 5$ / BA-a, and HP $\beta C D 15 / B A-a)$ with different weight percentage compositions were produced and their fibrous morphology was investigated by SEM imaging as shown in Fig. 2(a1-d1).

The effect of the solution composition on the conductivity, viscosity and the average fiber diameters were examined prior to curing studies. $\operatorname{HP} \beta C D(120 \%, w / v)$ was also used as a control to estimate the changes in the fibrous samples and Table 1 displays the related data for these samples. While the conductivity of the solutions was not influenced by the solution composition, significant increase was observed in solution viscosity depending on the composition of the electrospinning solutions. The highest solution viscosity was observed for HP $\beta C D 15 / B A-a$ solution due to the higher content of CTR. As anticipated, higher average fiber diameter was obtained for the electrospun HP $\beta C D 15 / B A-$ a microfibers since less stretching of the jet could occur during the electrospinning process [48]. On the other hand, the solution conductivities were very low and close to each other and the solution viscosity values were not that significant from each other for the other solutions (i.e. HP $\beta C D 15, H P \beta C D / B A-a$, and HP $\beta C D 5 / B A-a)$ and therefore, the average fiber diameter for the resulting electrospun fibers from these solutions did not exhibit significant differences.

Afterwards, the effect of thermal curing on these blend microfibers was investigated by stepwise curing method in the temperature range $150-225^{\circ} \mathrm{C}$ as BA-a monomer could polymerize by this method [47]. As a consequence of the curing study, it was found that HP $\beta C D 15$ fibrous membrane was not able to resist thermal curing. While this sample maintained its fibrous structure up to $200^{\circ} \mathrm{C}$, the fiber morphology was completely diminished, and transformed into a film when the temperature has reached $225^{\circ} \mathrm{C}$, as displayed in Fig. 2(b2). On the other hand, a significant thermal resistance was achieved in CTR and BA-a incorporated microfibers (PolyHP $\beta C D 5 /$ PolyBA-a, PolyHP $\beta C D 15 /$
PolyBA-a, Fig. 2(c2)-(d2) up to $225^{\circ} \mathrm{C}$. Here, it is evident that incorporating only BA-a or CTR is not sufficient enough for crosslinking HP $\beta C D$ FMs, yet, the combination of both compounds only enables the successful crosslinking as the electrospun HP $\beta C D$ FM can remain its fibrous structure at high temperature (i.e. $225^{\circ} \mathrm{C}$ ) during curing.

Further investigation was conducted by FT-IR spectroscopy to understand the structural changes of the FMs after thermal curing as it may indicate the successful crosslinking/polymerization of FM samples. Fig. 3 displays the chemical structures of HP $\beta C D$, CTR and BA-a (Fig. 3a) along with the changes in absorption peaks of FMs as a function of temperature intervals (Fig. 3b-e). Here, while the FM samples of HP $\beta C D / B A-a, H P \beta C D 5 / B A-a$ and HP $\beta C D 15 / B A-a$ were monitored up to $225^{\circ} \mathrm{C}$, HP $\beta C D 15$ cured up to $200^{\circ} \mathrm{C}$, since the fibrous structure of this sample was damaged after this temperature. Fig. $3 \mathrm{~b}$ displays the FT-IR spectra of HP $\beta C D 15$ before and after curing. Aselectrospun $\mathrm{HP} \beta C D 15$ sample has $\mathrm{C}=\mathrm{O}$ stretches $(1720$ and $1630 \mathrm{~cm}^{-1}$ ) which arise from citric acid [49] and it also has several stretching bands which are attributed to $\mathrm{C}-\mathrm{H}$ and $\mathrm{C}-\mathrm{O}$ vibrations located between 1035 and $1200 \mathrm{~cm}^{-1}$ due to the glycosidic bonds of CD [31] and citric acid ( $\mathrm{C}=\mathrm{O}$ vibrations) [49]. Nevertheless, thermal curing did not create any observable difference on the absorption peaks of $\mathrm{HP} \beta C D 15$. Only a slight reduction in the relative intensity of $\mathrm{C}=\mathrm{O}$ stretches (1720 and $1630 \mathrm{~cm}^{-1}$ ) is monitored, therefore, FT-IR is not a sufficient enough to determine possible crosslinking in this sample. On the other hand, for the samples containing BA-a (Fig. 3c-e) can easily be monitored by tracing the characteristic peaks of BA-a which are; the $\mathrm{C}-\mathrm{C}$ stretches at $1490 \mathrm{~cm}^{-1}$ and $\mathrm{C}-\mathrm{O}-\mathrm{C}$ stretches at $1230 \mathrm{~cm}^{-1}[50]$. Furthermore, these peaks are straightforward to distinguish in the spectra as they do not overlap with HP $\beta C D$ peaks. It is apparent that these characteristic peaks are gradually disappeared by thermal curing, indicating a possible crosslinking in $\mathrm{HP} \beta \mathrm{CD} / \mathrm{BA}-\mathrm{a}, \mathrm{HP} \beta \mathrm{CD} 5 / \mathrm{BA}-\mathrm{a}$, HP $\beta C D 15 / B A-a$ and successful production of PolyHP $\beta C D / P o l y B A-a$, PolyHP $\beta C D 5 / P o l y B A-a$ and PolyHP $\beta C D 15 / P o l y B A-a$ (Fig. 3c-e).

Possible crosslinking was further supported by studying thermal 

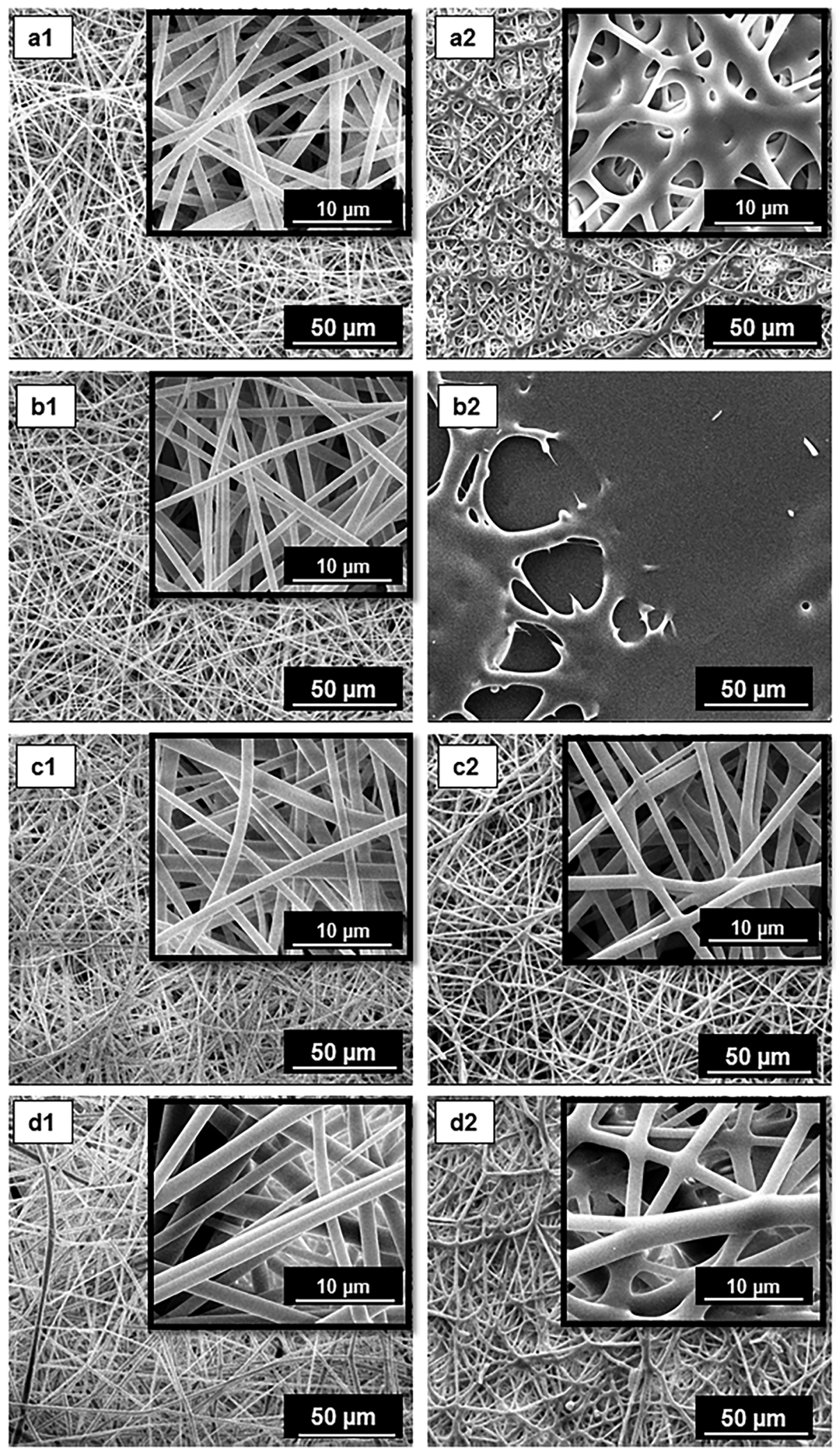

Fig. 2. SEM images of (a) HP $\beta C D / B A-a$ (b) HP $\beta C D 15$, (c) HP $\beta C D 5 / B A-a$, (d) HP $\beta C D 15 / B A-a$. (1) as-electrospun microfibers and (2) corresponding cured crosslinked microfibers.

properties of the FMs using TGA. Fig. 4 exhibits TGA thermograms of the BA-a and CTR powders, HPßCD, PolyHPßCD/PolyBA-a, PolyHP $\beta C D 15$, PolyHP $\beta C D 5 / P o l y B A-a$ and PolyHP $\beta C D 15 / P o l y B A-a$ FMs before and after curing. TGA curve of HP $\beta C D$ shows a residual loss $(\sim 4 \%)$ below $100{ }^{\circ} \mathrm{C}$ and thermal decomposition occurs around $345{ }^{\circ} \mathrm{C}$ which is slightly shifted to a higher degree $\left(362^{\circ} \mathrm{C}\right)$ in $\mathrm{HP} \beta \mathrm{CD} / \mathrm{BA}-\mathrm{a}$ (aselectrospun) FM as demonstrated in Fig. 4a. In addition, BA-a monomer exhibits two distinct weight loss steps below and above $240{ }^{\circ} \mathrm{C}$ due to the structural changes in oxazine ring. While as-electrospun FM (HP $\beta C D / B A-a)$ shows all these decomposition steps, thermally cured 
(a)

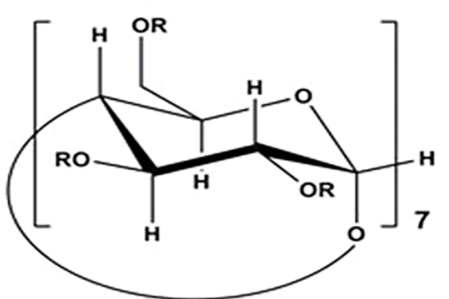

(HPßCD)<smiles>O=C(O)CC(O)(CC(=O)O)C(=O)O</smiles>

(CTR)
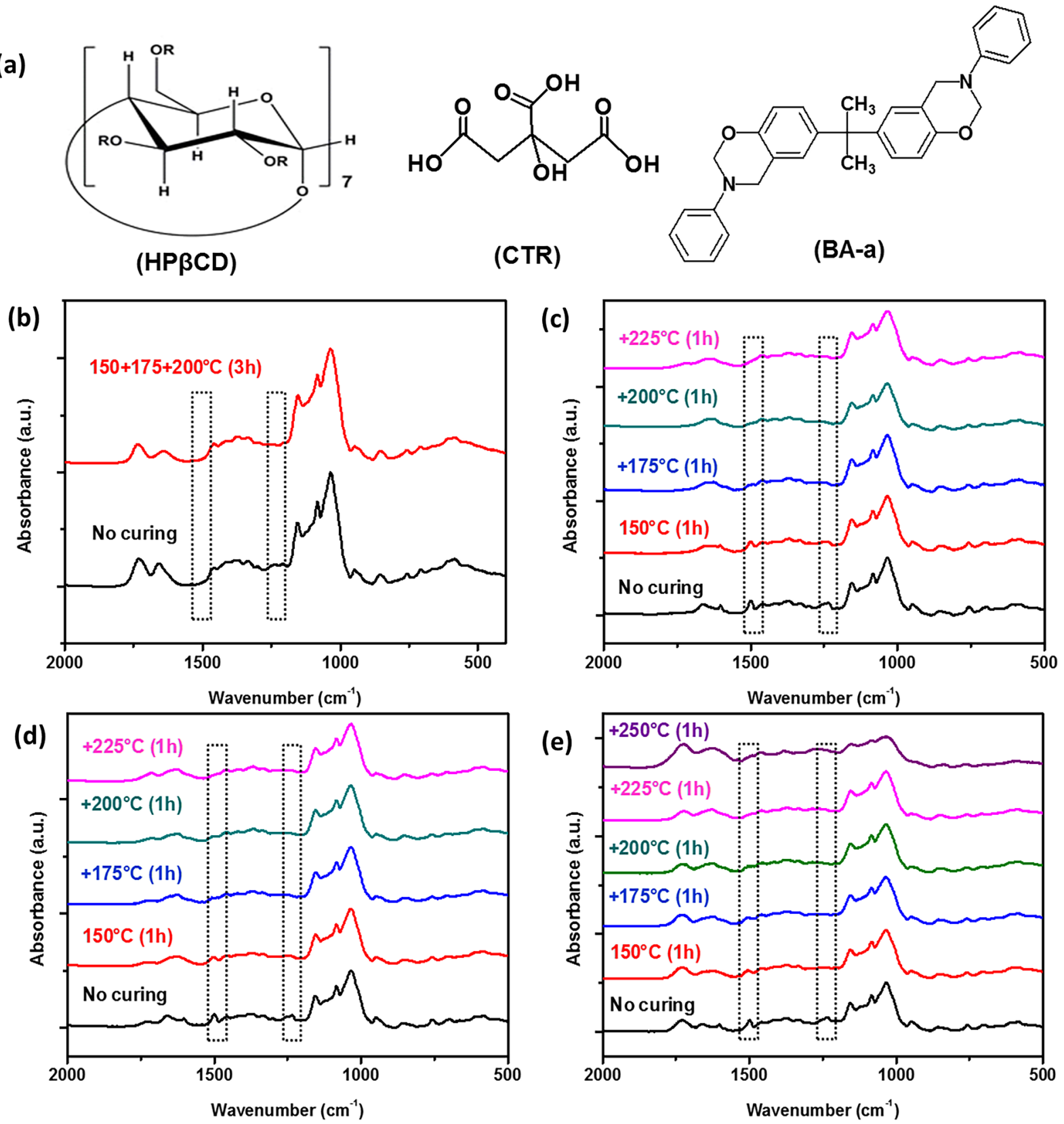

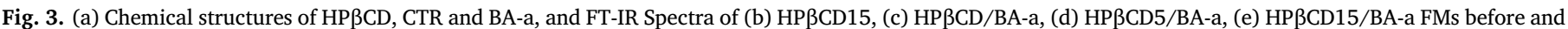
after thermal curing.

PolyHP $\beta$ CD/PolyBA-a FM displays only one distinct decomposition step around $360 \mathrm{~s}^{\circ} \mathrm{C}$. Also, as we anticipated, char yield of as-electrospun FM (HP $\beta C D / B A-a)$ increased from $17 \%$ to $19 \%$ by thermal curing, indicating slightly increased char yield in PolyHP $\beta C D / P o l y B A-a$ FM with respect to as-electrospun FM. Considering the char yield of $\mathrm{HP} \beta C D$ ( 7\%), PolyHPßCD/PolyBA-a FM showed significant increase in char yield. Fig. $4 \mathrm{~b}$ exhibits the TGA curves of as- electrospun HP $\beta C D 15$ and cured PolyHP $\beta C D 15$ FMs. CTR decomposition occurs within two distinct weight losses; while the first step is observed around $160 \mathrm{~s}{ }^{\circ} \mathrm{C}$, the complete decomposition happens below $300^{\circ} \mathrm{C}$. Likewise, CTR incorporated as-electrospun HP $\beta C D 15$ FM shows both CTR and HP $\beta C D$ decomposition steps. Regarding the char yield of as-electrospun (HP $\beta C D 15)$ and cured (PolyHP $\beta C D 15)$ FMs, no considerable difference was found. Also, the char yield of HP $\beta C D(\sim 7 \%)$ has only increased up to $12 \%$ which is mainly due to the absence of residual loss in these FMs. On the other hand, the highest char yield was obtained in the case of
PolyHP $\beta C D 5 / P o l y B A-a$ and PolyHP $\beta C D 15 /$ PolyBA-a FMs with $\sim 20.1 \%$ char yield (Fig. 4c and d), indicating higher thermal stability is achieved by the combination the properties of HP $\beta C D$, BA-a and CTR5 in these membranes.

Although FT-IR and TGA indicate possible crosslinking in BA-a and CTR incorporated HP $\beta C D$ FMs, yet, it was not clearly evident that crosslinking was adequate for providing structural integrity to these membranes. Thus, cured FMs were immersed into water to explore the success of crosslinking. It can be ascribed that even though pristine HP $\beta C D$ FM have great solubility in water (Fig. 5a), the crosslinked PolyHP $\beta C D / P o l y B A-a$ FMs should maintain their fibrous form in water due to the enhanced structural stability. Consequently, strong evidence of crosslinking was found when the stability of these FMs was tested in water. While PolyHP $\beta$ CD/PolyBA-a, PolyHP $\beta C D 15$, PolyHP $\beta C D 5 /$ PolyBA-a FMs were completely and immediately dissolved in water, PolyHP $\beta C D 15 / P o l y B A-a$ FM could maintain its structural stability as 

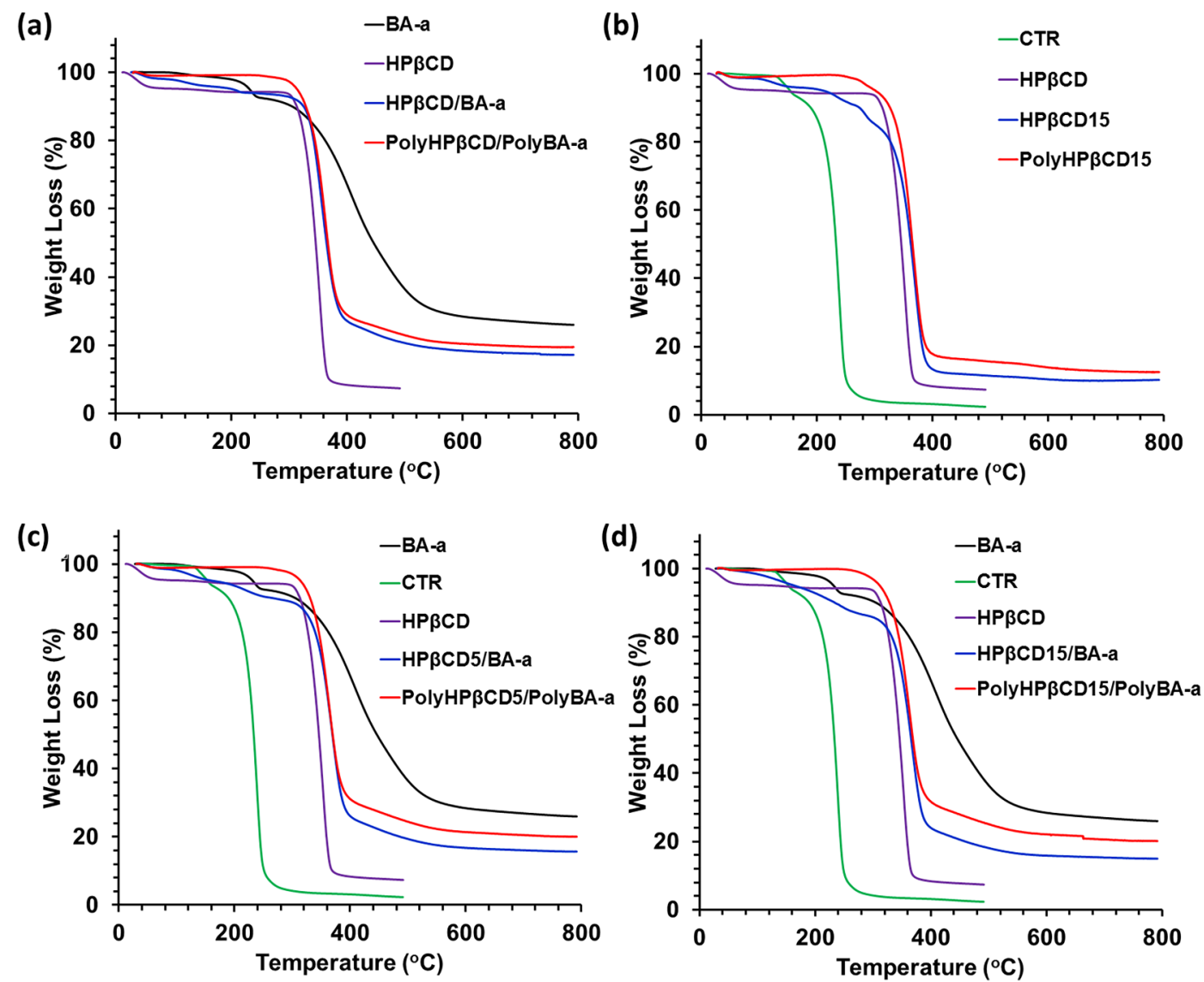

Fig. 4. TGA curves of BA-a, $C T R$ and $\operatorname{HP} \beta C D$ (a) $H P \beta C D / B A-a$, (b) $H P \beta C D 15$, (c) $H P \beta C D 5 / B A-a$, (d) HP $\beta C D 15 / B A-a$ microfibers before and after thermal curing.

(a)

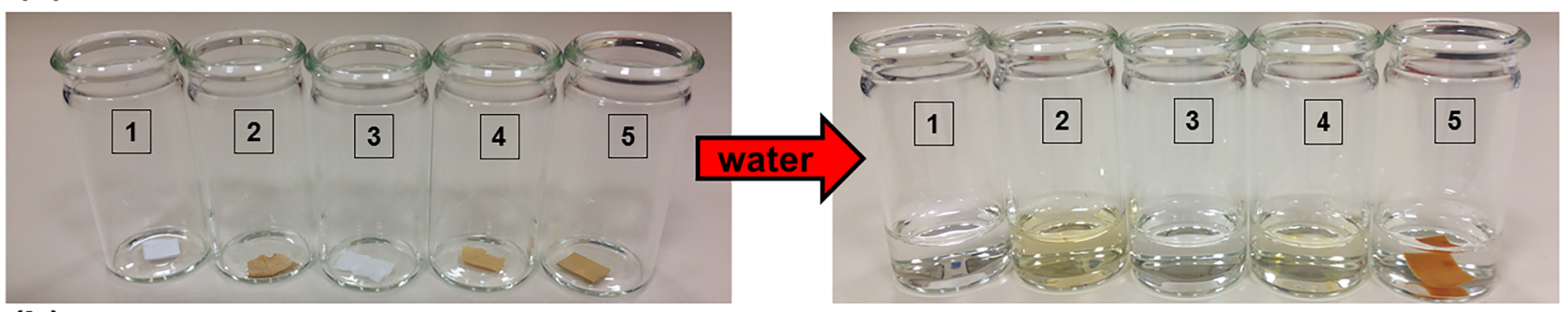

(b)

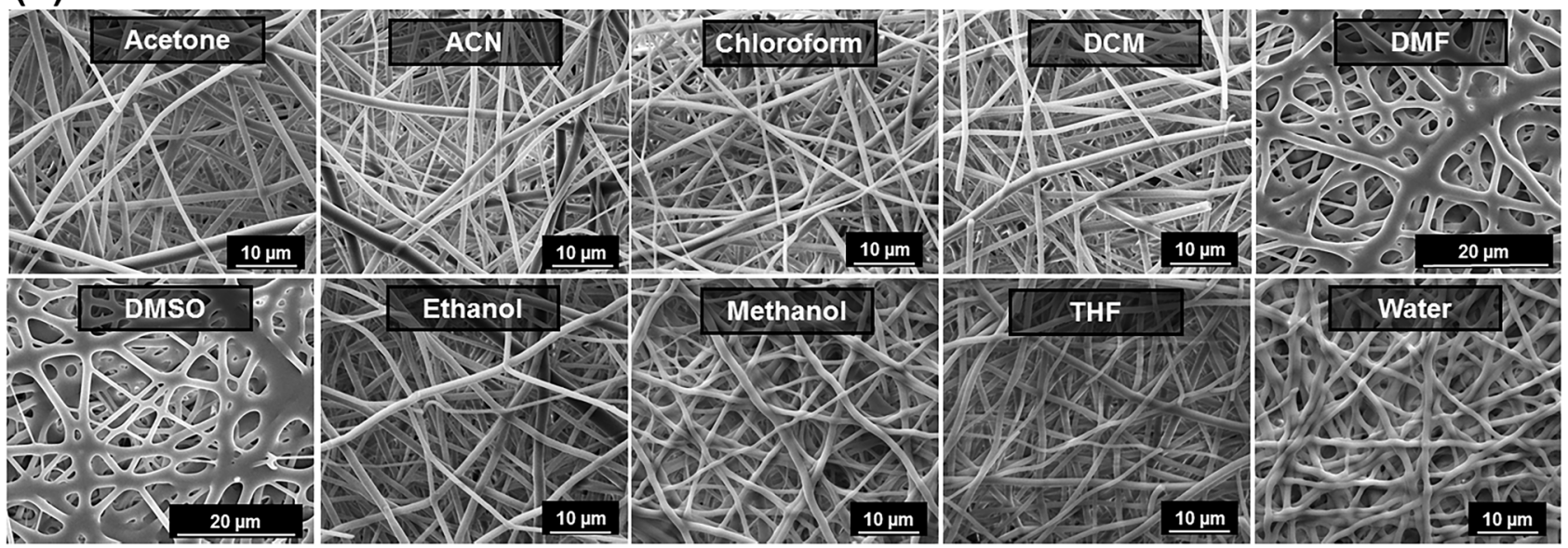

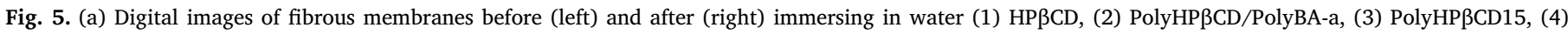
PolyHP $\beta C D 5 /$ PolyBA-a, (5) PolyHP $\beta C D 15 /$ PolyBA-a, (b) SEM images of PolyHP $\beta C D 15 /$ PolyBA-a microfibers after immersing in different solvents for overnight. 


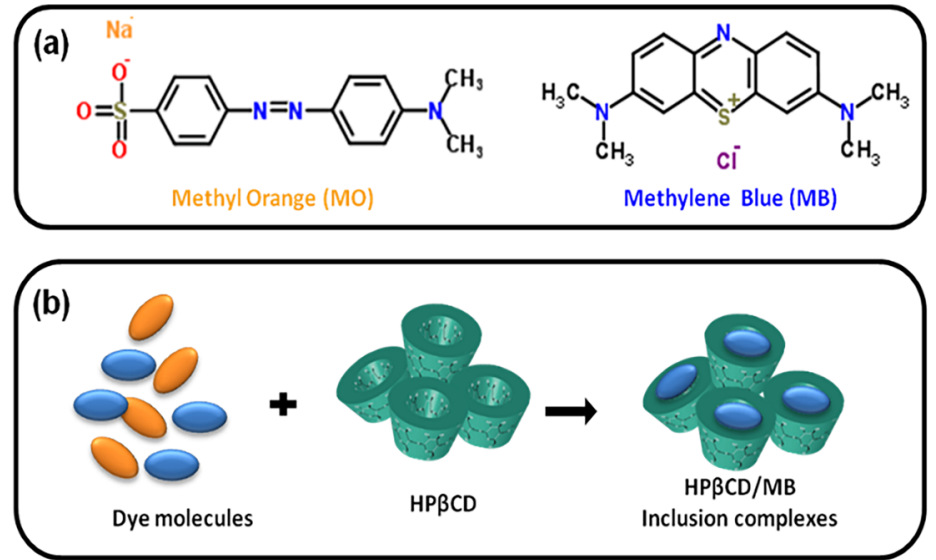

(c)

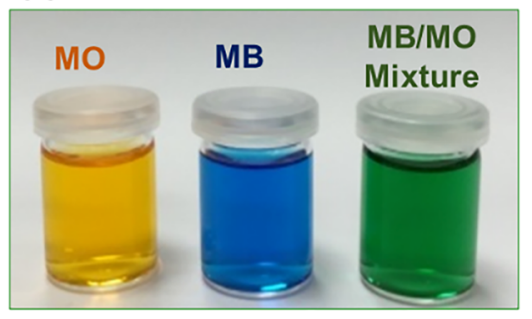

(e)

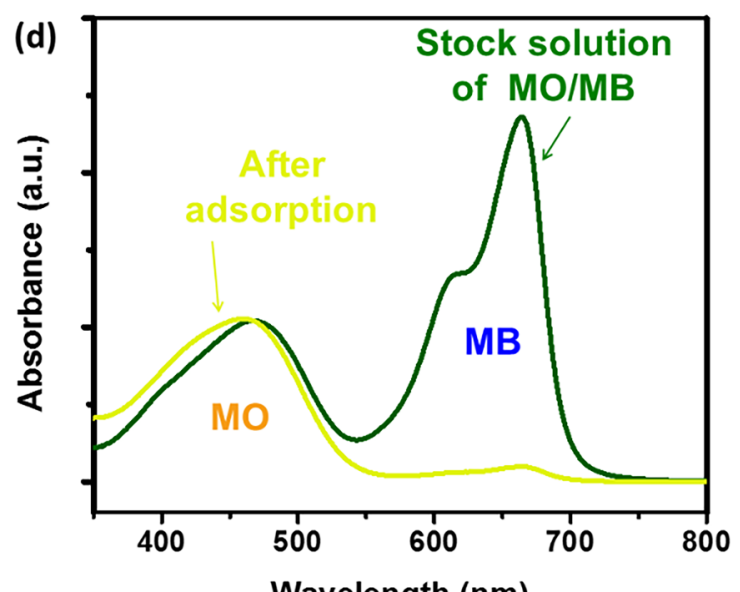

Wavelength $(\mathrm{nm})$

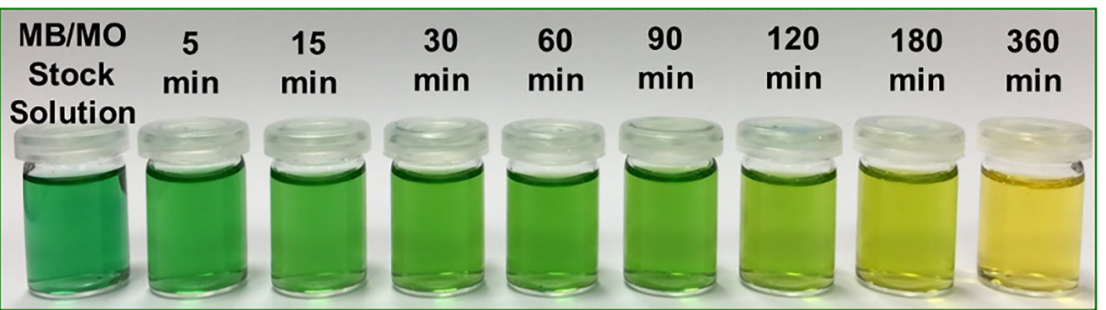

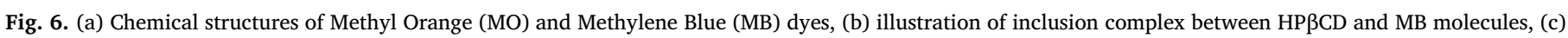

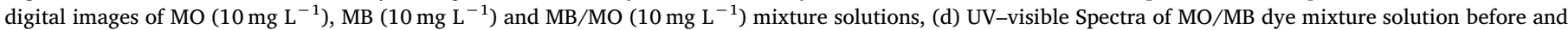
after adsorption, (e) Digital images of the MO/MB mixture solutions after treated with PolyHP 3 CD15/PolyBA-a FM at certain time intervals.

depicted in Fig. 5a. Therefore, it is concluded that complete crosslinking is only achieved in PolyHP $\beta C D 15 / P o l y B A-a$ FM. This study was further expanded by investigating the structural stability of PolyHPßCD15/PolyBA-a FM in various organic solvents such as acetone, ACN, chloroform, DMF, DMSO, ethanol, methanol and THF. Hence, PolyHP $\beta C D 15 / P o l y B A-a$ FM was immersed in these solvents overnight. Then, it was dried and its morphology was examined. As exhibited in Fig. 5b, whereas some of these solvents (i.e., DMF, DMSO, water) that can readily dissolve HP $\beta C D$ microfibers, PolyHP $\beta C D 15$ / PolyBA-a microfibers showed excellent structural integrity and kept its fibrous morphology in these solvents. Crosslinked PolyHP $\beta C D 15 /$ PolyBA-a membrane was able to preserve its fibrous form in all tested solvents, which might be attributed to higher degree of crosslinking in this sample. Only slight swelling was observed in DMF and DMSO which are very good solvents for HP $\beta C D$. Nevertheless, considering the very content of HP $\beta C D$ in crosslinked FM, such swelling is anticipated.

Based on the data obtained from SEM and solubility experiments, it was observed that both CTR and BA-a must be incorporated in order to achieve stable fibrous structure for PolyHP $\beta C D 15 /$ PolyBA-a microfibers. However, the insolubility of the crosslinked PolyHP $\beta C D 15 /$ PolyBA-a microfibers has limited the experimental evidences to propose an exact pathway for crosslinking. It is for sure that there is a crosslinking between HP $\beta C D$ and BA-a when the HP $\beta C D / B A-a$ microfibers were thermally cured (Fig. 2a), but, CTR is needed to have highly crosslinked and more stable PolyHP $\beta C D / P o l y B A-a$ microfibers. CTR is a well-known crosslinker to synthesize water-insoluble cyclodextrin polymers but there is a need of using sodium dihydrogen phosphate as a catalyst for obtaining such crosslinked insoluble cyclodextrin polymers $[51,52]$. Here, we did not use sodium dihydrogen phosphate but the electrospun fibers only consist of HP $\beta C D / C T R / B A-a$ in order to achieve thermally crosslinked PolyHP $\beta C D / P o l y B A-a$ microfibers. We anticipate that the crosslinking path is complex since both CTR and BA-a contribute to the crosslinking of $\mathrm{HP} \beta C D$, and BA-a is a resin which is known to become crosslinked polybenzoxazine by itself. It is possible that the crosslinking occurs between HP $\beta C D$ and CTR in the presence of BA-a at low temperatures (below $200^{\circ} \mathrm{C}$, Fig. 4) since CTR decomposes at lower temperature compared to HP $\beta C D$ and BA-a. Yet, HP $\beta C D$ and BA-a could thermally crosslinked but CTR is required to have highly crosslinked structure which resulted in more stable PolyHP $\beta C D / P o l y B A-a$ fibrous structure. Also, it must be noted that some BA-a molecules could interact by itself to form polybenzoxazine in the fiber matrix. In short, the crosslinking pathway seems to be complicated for the HPßCD/CTR/BAa system, which makes it difficult to propose a definite crosslinked structure for PolyHP $\beta C D / P o l y B A-a$ microfibers.

The enhanced structural stability in water and organic solvents may enable broad range of applications for PolyHP $\beta C D 15 /$ PolyBA-a FMs. Particularly, PolyHP $\beta C D 15 / P o l y B A-a$ FMs could be a promising material for water treatment applications due to the molecular separation ability of cyclodextrins. It is well-documented that $\mathrm{CD}$ molecules have the ability to form inclusion complex with specific molecules such as Methylene Blue (MB) [30,35,53]. However, the removal of organic contaminants cannot be explained by only inclusion complexation, the electrostatic attractions between dyes and cyclodextrin molecules are also crucial for the adsorption process. For instance, two oppositely charged dyes; Methylene Blue (cationic) and Methyl Orange (anionic) both have the ability to form host-guest interaction with $\mathrm{CD}$ molecules $[30,54]$. Nonetheless, cationic Methylene Blue dye can selectively be removed from Methylene Blue/Methyl Orange dye mixture by $\mathrm{CD}$ functional microfibers where electrostatic attractions play an important role for selective removal of Methylene Blue at basic conditions [35].

Therefore, we have investigated the removal ability of crosslinked PolyHP $\beta C D 15 / P o l y B A-a$ FMs for dye molecules which might be a promising material for water treatment applications if the dye selectivity is remained after crosslinking. To reveal this feature, molecular entrapment ability of PolyHP $\beta C D 15 /$ PolyBA-a FM was tested using Methylene Blue (MB, cationic dye) and Methyl Orange (MO, anionic dye) dyes as model compounds (Fig. 6a). PolyHPßCD15/PolyBA-a FM was placed in a mixture of $\mathrm{MB}\left(10 \mathrm{mg} \mathrm{L}^{-1}\right)$ and $\mathrm{MO}\left(10 \mathrm{mg} \mathrm{L}^{-1}\right)$ solutions to seek for the selectivity of the membrane. As we expected, PolyHP $\beta C D 15 / P o l y B A-a$ FM can selectively remove MB molecules from 
the solution by forming inclusion complex (Fig. 6b) [30]. The visual appearance of $\mathrm{MB}, \mathrm{MO}$ and a mixture of $\mathrm{MB} / \mathrm{MO}$ solutions are depicted in Fig. 6c. UV-visible spectra for MB removal from the mixture is displayed in Fig. $6 \mathrm{~d}$. As can be seen, while the absorption signal at 664 (MB) is diminished after adsorption, the signal for MO (464) nm remained unchanged, indicating the selectivity of PolyHP $\beta C D 15 /$ PolyBAa FM for MB dye over MO dye.

Time dependent dye removal experiments were performed with the same concentration solution to determine the required time interval for the effective removal of the dye molecules. Fig. 6e shows the digital images of the MO/MB mixture solutions after given time. As can be seen, complete removal was achieved within $6 \mathrm{~h}$. A green color of the $\mathrm{MO} / \mathrm{MB}$ mixture solution became yellow by the time, revealing only MB molecules adsorbed by PolyHP $\beta C D 15 /$ PolyBA-a membrane due to both inclusion complexation and electrostatic attractions. The affinity between positively charged MB molecules and hydroxyl groups of $\mathrm{CD}$ molecules further promote the efficient inclusion complexation between MB dye and CD cavity since electrostatic repulsion between MO and $\mathrm{CD}$ molecules inhibit the adsorption of MO from the MB/MO dye mixture [35].

In order to calculate the adsorption capacity of the PolyHP $\beta C D 15 /$ PolyBA-a FM, different concentrations of the MB solutions were prepared from 10 to $100 \mathrm{mg} \mathrm{L}^{-1}$. Fig. 7a illustrates the association between the adsorption capacity of PolyHP $\beta C D 15 / P o l y B A-a$ FM and equilibrium concentration of $\mathrm{MB}$ in solution. As displayed, the adsorption capacity increases in parallel with the increased MB concentration. The saturation adsorption capacity of PolyHP $\beta C D 15 /$ PolyBA-a FM was $46 \mathrm{mg} \mathrm{g}^{-1}$ at $100 \mathrm{mg} \mathrm{L}^{-1}$.

Furthermore, two different isotherm models; Langmuir and Freundlich were used for MB adsorption onto PolyHP $\beta C D 15 / P o l y B A-a$ FM to determine the adsorption process. According to Langmuir isotherm model, the adsorption occurs on a homogenous surface as a monolayer adsorption, which expresses that when one molecule of MB occupied a place, no more adsorption is possible in that site. In the case
Table 2

The constants of Langmuir and Freundlich isotherms and respective correlation coefficients for Methylene Blue adsorption on PolyHPßCD15/PolyBA-a FM.

\begin{tabular}{llllll}
\hline \multicolumn{2}{l}{ Langmuir parameters } & \multicolumn{4}{c}{ Freundlich Parameters } \\
\hline$q_{\mathrm{m}}\left(\mathrm{mg} \mathrm{g}^{-1}\right)$ & $\mathrm{K}_{\mathrm{L}}\left(\mathrm{L} \mathrm{mg}^{-1}\right)$ & $\mathrm{R}^{2}$ & $\mathrm{n}_{\mathrm{F}}$ & $\mathrm{K}_{\mathrm{F}}\left(\mathrm{L} \mathrm{g}^{-1}\right)$ & $\mathrm{R}^{2}$ \\
\hline 46.08 & 0.16 & 0.996 & 2.52 & 9.77 & 0.925 \\
\hline
\end{tabular}

of Freundlich isotherm model, the adsorption occurs on a heterogenous surface, which can accommodate more than one molecule at the same location. Fig. $7 \mathrm{~b}$ and $\mathrm{c}$ present the applied isotherm models for PolyHP $\beta C D 15 / P o l y B A-a$ FM. On the basis of the correlation coefficient $\left(\mathrm{R}^{2}\right)$ values, Langmuir model $\left(\mathrm{R}^{2}: 0.997\right)$ had a better fit for adsorption of MB than that of Freundlich model $\left(\mathrm{R}^{2}: 0.925\right)$. The adsorption characteristics of MB on PolyHP $\beta C D 15 / P o l y B A-a$ FM was monolayer adsorption, indicating possible inclusion complexation. Table 2 demonstrates the constant of isotherm models and their correlation coefficients. Additionally, the values of separation factors $\left(R_{L}\right)$ were calculated, which indicates whether the adsorption is favorable or not. When it is $0<R_{L}<1$, it is considered as favorable. If it is greater than 1 , it is considered as unfavorable and if it is 1 it is considered as linear. Hence, the separation factors $\left(\mathrm{R}_{\mathrm{L}}\right)$ were found between 0.068 and 0.421 for $\mathrm{MB}$, indicating favorable adsorption.

Based on the adsorption maximum, PolyHP $\beta C D 15 / P o l y B A-a$ FM did not show great adsorption capacity, yet PolyHP $\beta C D 15 / P o l y B A-a$ FM has shown structural stability along with selectivity which might be as important as showing good performance in separation applications. Further, regeneration of PolyHP $\beta C D 15 /$ PolyBA-a FM was studied to demonstrate the feasibility of fibrous membrane in water treatment applications. Desorption of MB from PolyHP $\beta C D 15 /$ PolyBA-a FM is recorded and provided in supplementary video. As can be seen in supplementary video recording, desorption occurs quite fast and it is possible to re-use the fibrous membrane. Hence, the removal efficiency
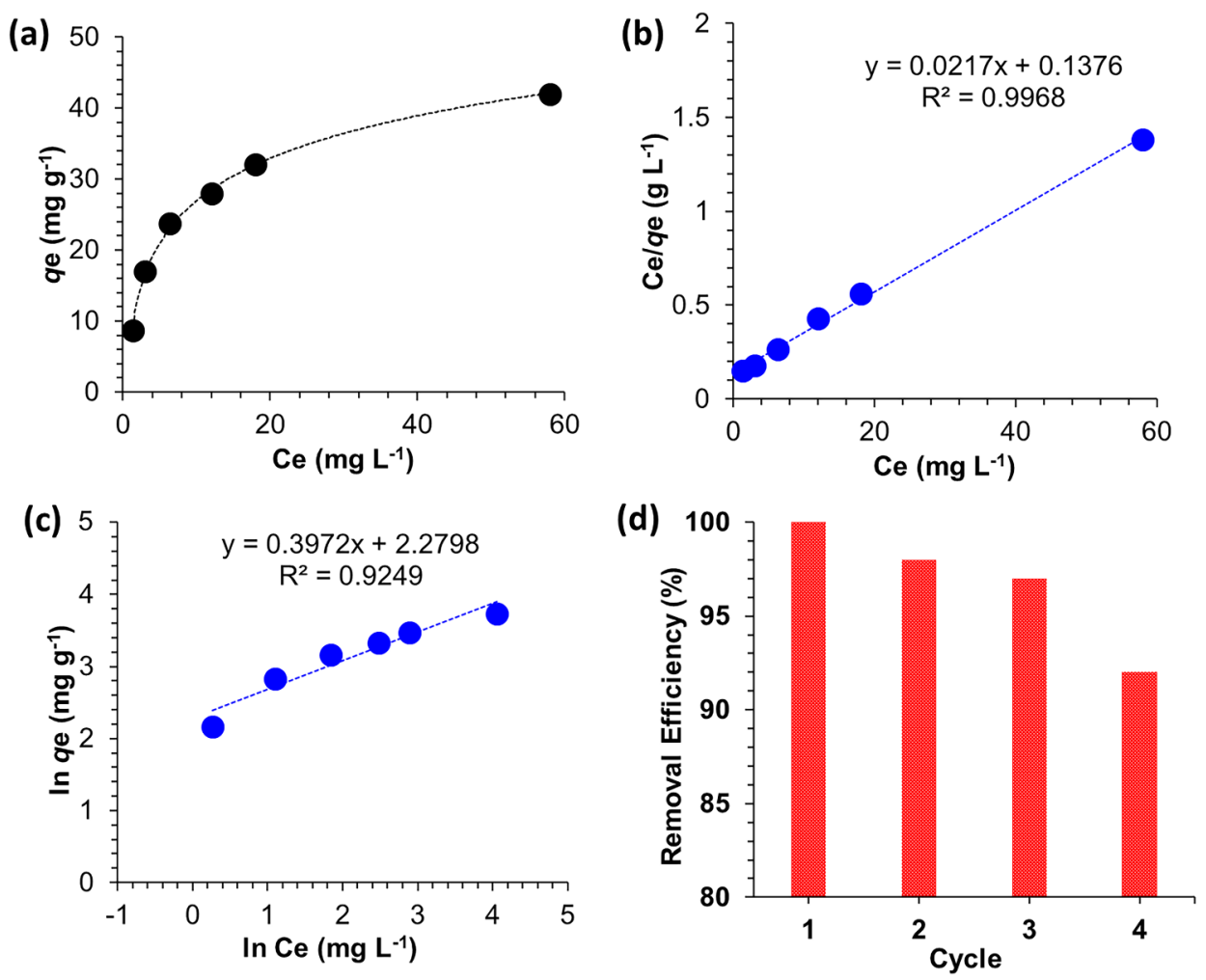

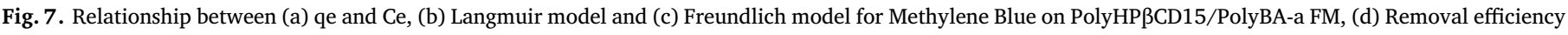
of PolyHP $\beta C D 15 /$ PolyBA-a FM for continuous MB adsorption. 
of PolyHPßCD15/PolyBA-a FM was still $92 \%$ after utilizing for four consecutive adsorption/desorption cycles, indicating an overall performance of the fibrous membrane (Fig. $7 \mathrm{~d}$ ). In addition to the performance of PolyHP $\beta C D 15 /$ PolyBA-a FM, this study presents a new approach to design and crosslink cyclodextrin microfibers to further extent the knowledge and the application of CDs in molecular filtration applications.

\section{Conclusion}

In conclusion, crosslinked cyclodextrin microfibers can be obtained by blending HP $\beta C D$ with BA-a and CTR in DMF prior to electrospinning and then subsequent thermal curing. Structural changes of the fibrous membranes were monitored using FT-IR spectroscopy which indicates the changes of oxazine ring in BA-a monomer by thermal curing. Thermal properties of FMs were studied by TGA, which shows that CTR and BA-a incorporated crosslinked microfibers show significant improvement in thermal stability. While CTR and BA-a incorporated crosslinked FMs can maintain their fibrous morphology, the absence of CTR in FMs could cause the loss of fibrous morphology due to the insufficient crosslinking. Moreover, produced crosslinked PolyHP $\beta C D 15 /$ PolyBA-a microfibers have exhibited an enhanced stability in water as well as in several organic solvents, suggesting self-standing PolyHPßCD15/PolyBA-a FM could be a promising material for molecular separation applications. Therefore, dye adsorption ability of PolyHPßCD15/PolyBA-a FM was investigated and it showed excellent selectivity against $\mathrm{MB}$ when the mixture of $\mathrm{MB} / \mathrm{MO}$ is used. PolyHPßCD15/PolyBA-a FM can remove MB molecules from an aqueous system without having any damage in its fibrous morphology within $6 \mathrm{~h}$. Regeneration of the fibrous membranes was also possible and it could be used in continuous adsorption/desorption experiments. Consequently, this work may provide a straightforward method for the further design and development of PolyCD/PolyBenzoxazine microfibers for various applications.

\section{Data availability statement}

The raw/processed data required to reproduce these findings cannot be shared at this time due to technical or time limitations.

\section{Author contributions}

Y.E.D. and B.S. equally contributed to the manuscript. The manuscript was written through contributions of all authors. All authors have given approval to the final version of the manuscript.

\section{Appendix A. Supplementary material}

Supplementary data to this article can be found online at https:// doi.org/10.1016/j.eurpolymj.2019.08.005.

\section{References}

[1] J. Szejtli, Introduction and general overview of cyclodextrin chemistry, Chem. Rev. 98 (5) (1998) 1743-1754.

[2] A.R. Hedges, Industrial applications of cyclodextrins, Chem. Rev. 98 (5) (1998) 2035-2044.

[3] M.V. Rekharsky, Y. Inoue, Complexation thermodynamics of cyclodextrins, Chem. Rev. 98 (5) (1998) 1875-1918.

[4] M.E. Davis, M.E. Brewster, Cyclodextrin-based pharmaceutics: past, present and future, Nat. Rev. Drug Discov. 3 (2004) 1023.

[5] F.J. Otero-Espinar, J.J. Torres-Labandeira, C. Alvarez-Lorenzo, J. Blanco-Méndez, Cyclodextrins in drug delivery systems, J. Drug Deliv. Sci. Tech. 20 (4) (2010) 289-301.

[6] C. Muankaew, T. Loftsson, Cyclodextrin-based formulations: a non-invasive platform for targeted drug delivery, Basic Clin. Pharmacol. Toxicol. 122 (1) (2018) $46-55$.

[7] Z.I. Yildiz, A. Celebioglu, T. Uyar, Polymer-free electrospun nanofibers from sulfobutyl ether7-beta-cyclodextrin (SBE7- $\beta$-CD) inclusion complex with sulfisoxazole:
Fast-dissolving and enhanced water-solubility of sulfisoxazole, Int. J. Pharm. 531 (2) (2017) 550-558.

[8] M.D. Moya-Ortega, C. Alvarez-Lorenzo, A. Concheiro, T. Loftsson, Cyclodextrinbased nanogels for pharmaceutical and biomedical applications, Int. J. Pharm. 428 (1) (2012) 152-163.

[9] F. van de Manakker, T. Vermonden, C.F. van Nostrum, W.E. Hennink, Cyclodextrinbased polymeric materials: synthesis, properties, and pharmaceutical/biomedical applications, Biomacromolecules 10 (12) (2009) 3157-3175.

[10] S. Loethen, J.M. Kim, D.H. Thompson, Biomedical applications of cyclodextrin based polyrotaxanes, Polym Rev. 47 (3) (2007) 383-418.

[11] R. Mejia-Ariza, L. Graña-Suárez, W. Verboom, J. Huskens, Cyclodextrin-based supramolecular nanoparticles for biomedical applications, J. Mater. Chem. B 5 (1) (2017) 36-52.

[12] Z. Aytac, T. Uyar, Antioxidant activity and photostability of $\alpha$-tocopherol/ $\beta$-cyclodextrin inclusion complex encapsulated electrospun polycaprolactone nanofibers, Eur. Polym. J. 79 (2016) 140-149.

[13] É. Fenyvesi, M. Vikmon, L. Szente, Cyclodextrins in food technology and human nutrition: benefits and limitations, Crit. Rev. Food Sci. Nutr. 56 (12) (2016) 1981-2004.

[14] C. Sebaaly, C. Charcosset, S. Fourmentin, H. Greige-Gerges, Potential Applications of Cyclodextrin Inclusion Complexes, Liposomes, and Drug-in-Cyclodextrin-inLiposome in Food Industry and Packaging, in: A.M. Grumezescu, A.M. Holban (Eds.), Role of Materials Science in Food Bioengineering, Academic Press, 2018, pp. 187-234

[15] Z. Aytac, N.O.S. Keskin, T. Tekinay, T. Uyar, Antioxidant $\alpha$-tocopherol/ $\gamma$-cyclodextrin-inclusion complex encapsulated poly(lactic acid) electrospun nanofibrous web for food packaging, J. Appl. Polym. Sci. 134 (21) (2017).

[16] C.-D. Radu, O. Parteni, L. Ochiuz, Applications of cyclodextrins in medical textiles-review, J. Controlled Release 224 (2016) 146-157.

[17] T. Uyar, R. Havelund, J. Hacaloglu, F. Besenbacher, P. Kingshott, Functional electrospun polystyrene nanofibers incorporating alpha-, beta-, and gamma-cyclodextrins: comparison of molecular filter performance, ACS Nano 4 (9) (2010) 5121-5130.

[18] A. Alsbaiee, B.J. Smith, L. Xiao, Y. Ling, D.E. Helbling, W.R. Dichtel, Rapid removal of organic micropollutants from water by a porous $\beta$-cyclodextrin polymer, Nature 529 (2015) 190.

[19] S. Kawano, T. Kida, K. Miyawaki, Y. Noguchi, E. Kato, T. Nakano, M. Akashi, Cyclodextrin polymers as highly effective adsorbents for removal and recovery of polychlorobiphenyl (PCB) contaminants in insulating oil, Environ. Sci. Technol. 48 (14) (2014) 8094-8100.

[20] E. Baruch-Teblum, Y. Mastai, K. Landfester, Miniemulsion polymerization of cyclodextrin nanospheres for water purification from organic pollutants, Eur. Polym. J. 46 (8) (2010) 1671-1678.

[21] L. Szente, J. Szejtli, Highly soluble cyclodextrin derivatives: chemistry, properties, and trends in development, Adv. Drug Delivery Rev. 36 (1) (1999) 17-28.

[22] A. Celebioglu, T. Uyar, Electrospinning of nanofibers from non-polymeric systems: polymer-free nanofibers from cyclodextrin derivatives, Nanoscale 4 (2) (2012) 621-631.

[23] J.L. Manasco, C.D. Saquing, C. Tang, S.A. Khan, Cyclodextrin fibers via polymerfree electrospinning, RSC Adv. 2 (9) (2012) 3778-3784.

[24] P. Vass, B. Démuth, A. Farkas, E. Hirsch, E. Szabó, B. Nagy, S.K. Andersen, T. Vigh, G. Verreck, I. Csontos, G. Marosi, Z.K. Nagy, Continuous alternative to freeze drying: Manufacturing of cyclodextrin-based reconstitution powder from aqueous solution using scaled-up electrospinning, J. Controlled Release 298 (2019) $120-127$.

[25] W. Zhang, M. Chen, B. Zha, G. Diao, Correlation of polymer-like solution behaviors with electrospun fiber formation of hydroxypropyl- $\beta$-cyclodextrin and the adsorption study on the fiber, Phys. Chem. Chem. Phys. 14 (27) (2012) 9729-9737.

[26] F. Topuz, T. Uyar, Influence of hydrogen-bonding additives on electrospinning of cyclodextrin nanofibers, ACS Omega 3 (12) (2018) 18311-18322.

[27] F. Topuz, T. Uyar, Electrospinning of cyclodextrin functional nanofibers for drug delivery applications, Pharmaceutics 11 (1) (2018) 6.

[28] Z. Aytac, Z.I. Yildiz, F. Kayaci-Senirmak, N.O. San Keskin, S.I. Kusku, E. Durgun, T. Tekinay, T. Uyar, Fast-dissolving, prolonged release, and antibacterial cyclodextrin/limonene-inclusion complex nanofibrous webs via polymer-free electrospinning, J. Agric. Food. Chem. 64 (39) (2016) 7325-7334.

[29] A. Celebioglu, T. Uyar, Electrospun gamma-cyclodextrin $(\gamma-C D)$ nanofibers for the entrapment of volatile organic compounds, RSC Adv. 3 (45) (2013) 22891-22895.

[30] A. Celebioglu, Z.I. Yildiz, T. Uyar, Electrospun crosslinked poly-cyclodextrin nanofibers: Highly efficient molecular filtration thru host-guest inclusion complexation, Sci. Rep. 7 (1) (2017).

[31] A. Celebioglu, F. Topuz, T. Uyar, Water-insoluble hydrophilic electrospun fibrous mat of cyclodextrin-epichlorohydrin polymer as highly effective sorbent, ACS Appl. Polym. Mater. 1 (1) (2019) 54-62.

[32] A. Celebioglu, F. Topuz, Z.I. Yildiz, T. Uyar, Efficient removal of polycyclic aromatic hydrocarbons and heavy metals from water by electrospun nanofibrous polycyclodextrin membranes, ACS Omega 4 (4) (2019) 7850-7860.

[33] A. Celebioglu, S. Demirci, T. Uyar, Cyclodextrin-grafted electrospun cellulose acetate nanofibers via "Click" reaction for removal of phenanthrene, Appl. Surf. Sci. 305 (2014) 581-588

[34] M. Forouharshad, M. Putti, A. Basso, M. Prato, O. Monticelli, Biobased system composed of electrospun sc-PLA/POSS/cyclodextrin fibers to remove water pollutants, ACS Sustain. Chem. Eng. 3 (11) (2015) 2917-2924.

[35] R. Zhao, Y. Wang, X. Li, B. Sun, C. Wang, Synthesis of $\beta$-cyclodextrin-based electrospun nanofiber membranes for highly efficient adsorption and separation of methylene blue, ACS Appl. Mater. Interfaces 7 (48) (2015) 26649-26657. 
[36] Z. Wei, Y. Liu, H. Hu, J. Yu, F. Li, Biodegradable poly(butylene succinate-co-terephthalate) nanofibrous membranes functionalized with cyclodextrin polymer for effective methylene blue adsorption, RSC Adv. 6 (110) (2016) 108240-108246.

[37] A.I. Schäfer, K. Stelzl, M. Faghih, S. Sen Gupta, K.R. Krishnadas, S. Heißler, T. Pradeep, Poly(ether sulfone) nanofibers impregnated with $\beta$-cyclodextrin for increased micropollutant removal from water, ACS Sustain. Chem. Eng. 6 (3) (2018) 2942-2953.

[38] H. Ishida, T. Agag, Handbook of Benzoxazine Resins, Elsevier, Netherlands, 2011.

[39] H. Ishida, P. Froimowicz, Advanced and Emerging Polybenzoxazine Science and Technology, Elsevier, Amsterdam, 2017.

[40] N.N. Ghosh, B. Kiskan, Y. Yagci, Polybenzoxazines-new high performance thermosetting resins: synthesis and properties, Prog. Polym. Sci. 32 (11) (2007) 1344-1391.

[41] O.S. Taskin, B. Kiskan, A. Aksu, N. Balkis, J. Weber, Y. Yagci, Polybenzoxazine: a powerful tool for removal of mercury salts from water, Chem-Eur. J. 20 (35) (2014) 10953-10958.

[42] Y.L. Kobzar, I.M. Tkachenko, V.N. Bliznyuk, V.V. Shevchenko, Fluorinated polybenzoxazines as advanced phenolic resins for leading-edge applications, React. Funct. Polym. 133 (2018) 71-92.

[43] Y. Ertas, T. Uyar, Main-chain polybenzoxazine nanofibers via electrospinning, Polymer 55 (2) (2014) 556-564.

[44] Y. Ertas, T. Uyar, Cross-linked main-chain polybenzoxazine nanofibers by photo and thermal curing; stable at high temperatures and harsh acidic conditions, Polymer 84 (2016) 72-80.

[45] B. Satilmis, T. Uyar, Fabrication of thermally crosslinked hydrolyzed polymers of intrinsic microporosity (HPIM)/polybenzoxazine electrospun nanofibrous membranes, Macromol. Chem. Phys. 220 (1) (2019) 1800326.

[46] P. Gupta, C. Elkins, T.E. Long, G.L. Wilkes, Electrospinning of linear homopolymers of poly(methyl methacrylate): exploring relationships between fiber formation, viscosity, molecular weight and concentration in a good solvent, Polymer 46 (13) (2005) 4799-4810.

[47] X. Ning, H. Ishida, Phenolic materials via ring-opening polymerization: Synthesis and characterization of bisphenol-A based benzoxazines and their polymers, $\mathrm{J}$ Polym. Sci., Part A: Polym. Chem. 32 (6) (1994) 1121-1129.

[48] T. Uyar, F. Besenbacher, Electrospinning of uniform polystyrene fibers: The effect of solvent conductivity, Polymer 49 (24) (2008) 5336-5343.

[49] S. Bureau, D. Cozzolino, C.J. Clark, Contributions of Fourier-transform mid infrared (FT-MIR) spectroscopy to the study of fruit and vegetables: a review, Postharvest Biol. Technol. 148 (2019) 1-14.

[50] J. Dunkers, H. Ishida, Vibrational assignments of 3-alkyl-3,4-dihydro-6-methyl-2H1,3-benzoxazines in the fingerprint region, Spectrochim. Acta Part A Mol. Biomol Spectrosc. 51 (6) (1995) 1061-1074.

[51] S. Bednarz, M. Lukasiewicz, W. Mazela, M. Pajda, W. Kasprzyk, Chemical structure of poly( $\beta$-cyclodextrin-co-citric acid), J. Appl. Polym. Sci. 119 (6) (2011) 3511-3520.

[52] D. Zhao, L. Zhao, C.-S. Zhu, W.-Q. Huang, J.-L. Hu, Water-insoluble $\beta$-cyclodextrin polymer crosslinked by citric acid: synthesis and adsorption properties toward phenol and methylene blue, J. Incl. Phenom. Macrocycl. Chem. 63 (3) (2009) 195-201.

[53] F. Zhao, E. Repo, D. Yin, Y. Meng, S. Jafari, M. Sillanpää, EDTA-cross-linked $\beta$ cyclodextrin: an environmentally friendly bifunctional adsorbent for simultaneous adsorption of metals and cationic dyes, Environ. Sci. Technol. 49 (17) (2015) 10570-10580.

[54] J. Carrazana, B. Reija, P.R. Cabrer, W. Al-Soufi, M. Novo, J.V. Tato, Complexation of methyl orange with $ß$-cyclodextrin: detailed analysis and application to quantification of polymer-bound cyclodextrin, Supramol. Chem. 16 (8) (2004) 549-559. 